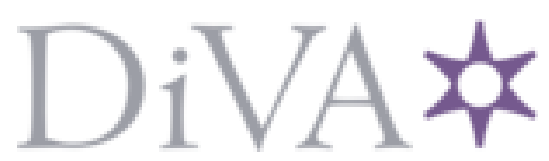

http://www.diva-portal.org

This is the published version of a paper published in Journal of Acoustical Society of America.

Citation for the original published paper (version of record):

Larsson, C., Öhlund, O. (2014)

Amplitude modulation of sound from wind turbines under various meteorological conditions.

Journal of Acoustical Society of America, 135(1): 67-73

http://dx.doi.org/10.1121/1.4836135

Access to the published version may require subscription.

N.B. When citing this work, cite the original published paper.

Copyright (2014) Acoustical Society of America. This article may be downloaded for personal use only. Any other use requires prior permission of the author and the Acoustical Society of America." Link to article on journal website: http://link.aip.org/link/?JAS/135/67\&aemail=author

Permanent link to this version:

http://urn.kb.se/resolve?urn=urn:nbn:se:uu:diva-215584 


\title{
Amplitude modulation of sound from wind turbines under various meteorological conditions
}

\author{
Conny Larsson ${ }^{\text {a) }}$ and Olof Öhlund \\ Department of Earth Sciences, Uppsala University, Villavägen 16, SE-752 36 Uppsala, Sweden
}

(Received 6 March 2012; revised 28 October 2013; accepted 12 November 2013)

\begin{abstract}
Wind turbine (WT) sound annoys some people even though the sound levels are relatively low. This could be because of the amplitude modulated "swishing" characteristic of the turbine sound, which is not taken into account by standard procedures for measuring average sound levels. Studies of sound immission from WTs were conducted continually between 19 August 2011 and 19 August 2012 at two sites in Sweden. A method for quantifying the degree and strength of amplitude modulation (AM) is introduced here. The method reveals that AM at the immission points occur under specific meteorological conditions. For WT sound immission, the wind direction and sound speed gradient are crucial for the occurrence of AM. Interference between two or more WTs could probably enhance AM. The mechanisms by which WT sound is amplitude modulated are not fully understood. (C) 2014 Acoustical Society of America. [http://dx.doi.org/10.1121/1.4836135]
\end{abstract}

PACS number(s): 43.28.Gq, 43.28.Bj, 43.28.Hr [PSW]

Pages: $67-73$

\section{INTRODUCTION}

Growing interest in renewable energy sources has led to an increased number of wind turbines (WTs) installed at various locations. The public is generally very supportive of the use of wind as an energy source. When planning new WT installations, the locations are evaluated, and questions are commonly asked about the sound levels and whether they will disturb people. Studies of sound annoyance have demonstrated that people are disturbed by WT sound at lower sound levels than other sound sources, ${ }^{1-3}$ possibly due to the specific characteristics of WT sound. WT sound is amplitude modulated in time as the blades pass through the air in what is often referred to as a rhythmic "swish." The mechanisms of this phenomenon are not fully understood, but various explanations have been proposed. Oerlemans ${ }^{4,5}$ demonstrated that the swish sound, as perceived on the ground, is produced mainly by the downward movement of the turbine blades. According to Oerlemans, this is because of the directivity of the WT trailing edge sound. Sound produced by the downward movement of the blade is directed more toward the ground than sound produced by the upward movement. Sudden changes in the sound emitted by the WTs and interference patterns have also been discussed by van den Berg. ${ }^{6,7}$ van den Berg stated that the amplitude modulation (AM) occurs because of changes in the sound source when the angle of attack between the wind and WT blades is changing. According to van den Berg, the synchronizing of sound between different WTs during propagation in a stable atmosphere could explain the thumping noise heard at greater distances from WTs.

The Swedish Energy Agency is financially supporting Uppsala University to carry out an extensive project measuring WT sound at three sites in Sweden. Acoustical and meteorological measurements are being made continuously for $2 \mathrm{yr}$ in two forested areas and one area near a bay. At one

\footnotetext{
a) Author to whom correspondence should be addressed. Electronic mail: conny.larsson@met.uu.se
}

location in southern Sweden, sound propagation is being studied within a forest; at the second forest station, located in northern part of Sweden, sound propagation is being studied over a heterogeneous terrain with typical height deviations of $100 \mathrm{~m}$. These sites are representative of typical Swedish conditions, which are fairly common in other geographical locations around the world. The project aim is to improve our knowledge of sound propagation from WTs, especially over varying terrain and under varying weather conditions. The stations are located in very quiet areas with only small sound disturbances from the neighborhood.

This paper discusses measurements made at the two land-based sites for 1 year and case studies performed at different distances from the measured WT sound source. The observed AM is discussed with a focus on the propagation path of the sound waves. The paper also investigates whether the sound characteristics measured at a certain distance from WTs depend on meteorological conditions.

\section{MEASUREMENT SITES}

\section{A. The Ryningsnäs site}

At the Ryningsnäs site located in southern Sweden $\left(57.28^{\circ} \mathrm{N}, 15.99^{\circ} \mathrm{E}\right)$ (see Fig. 1), two WTs stand in a relatively flat forested landscape. The turbines are two Nordex $2500 \mathrm{LS}$ units (2.5 MW) with hub heights of 80 and $100 \mathrm{~m}$ (the northern WT is taller). The surroundings are quiet. A road between Målilla and Kalmar is located approximately $1.7 \mathrm{~km}$ south of the acoustical measurement stations and carries some traffic.

\section{B. The Dragaliden site}

The Dragaliden site is located in northern Sweden $\left(65.44^{\circ} \mathrm{N}, 20.52^{\circ} \mathrm{E}\right)$. The landscape is heterogeneous with hills extending $400-500 \mathrm{~m}$ above sea level and is covered with forest and swamp. The area is very sparsely populated, with six people living in Strömnäs approximately $1 \mathrm{~km}$ from the acoustical measurement station. Through this village runs a road bearing very little traffic. 


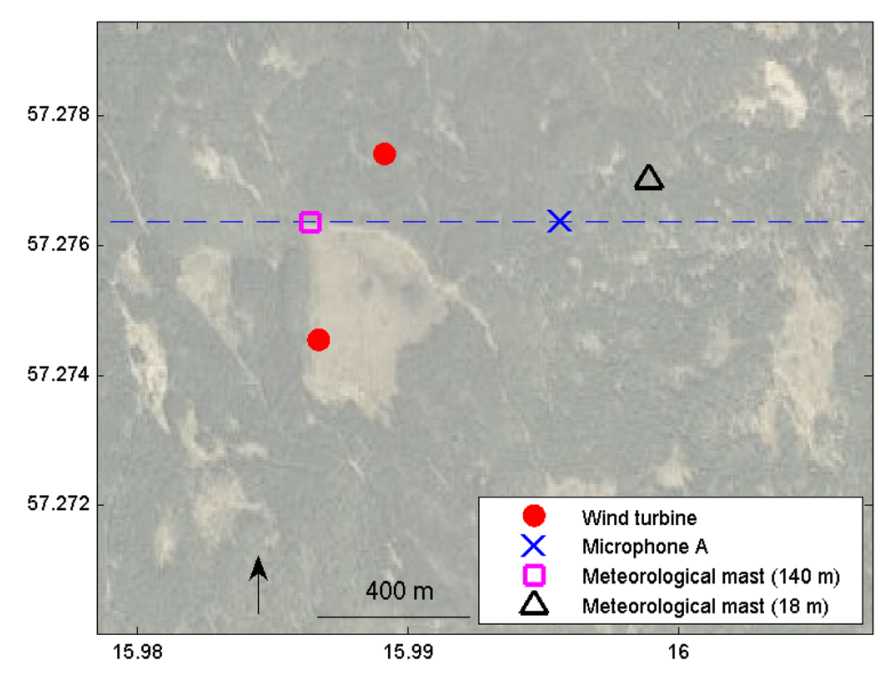

FIG. 1. (Color online) The Ryningsnäs site. Microphone position A is the stationary immission point. The sound propagation direction of interest for the Ryningsnäs site (indicated by the dashed line) is $90^{\circ}$ used in Eq. (3) to be able to calculate the sound speed in Eq. (2) (courtesy of Google Earth).

Twelve WTs were recently erected on the hill of Dragaliden, and the wind farm was in full operation in December 2010. Acoustical measurements are made continually approximately $1 \mathrm{~km}$ northeast of the turbines at microphone position B in Fig. 2. The ground height difference between the WTs and microphone position B is approximately $50 \mathrm{~m}$. The turbines are Enercon - E82 units (2 MW) with hub heights of 108 and $138 \mathrm{~m}$ (numbers three and six in the front row, counting from the west, are taller). These are the first twelve WTs of a large project comprising a total of 1101 WTs planned for an area of approximately $500 \mathrm{~km}^{2}$ in the region.

\section{MEASUREMENTS}

\section{A. Acoustical measurements}

Acoustical measurements are made at a height of $1.5 \mathrm{~m}$ inside the forest using a Norsonic Nor140 sound level meter

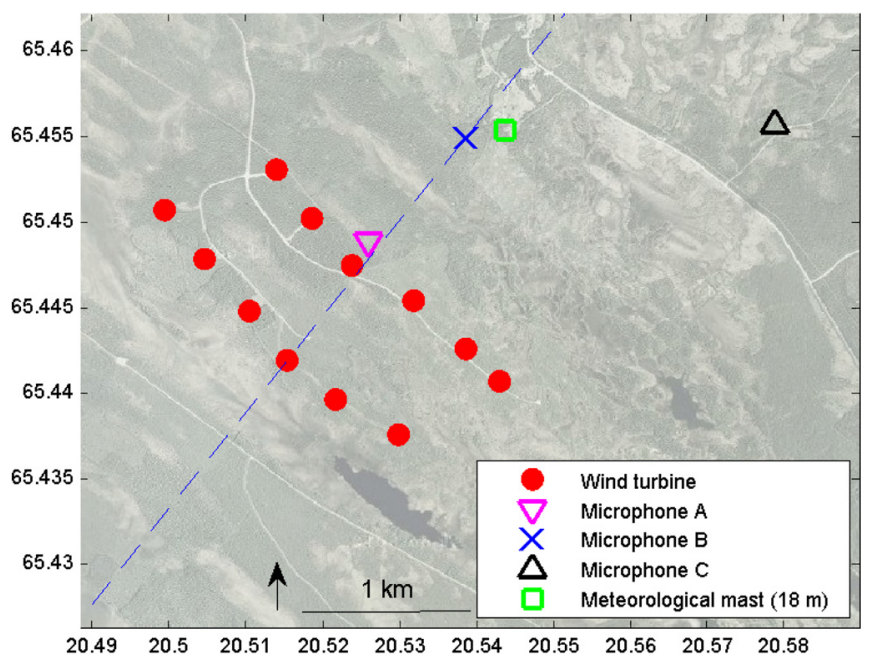

FIG. 2. (Color online) The Dragaliden site. Microphone position B is the stationary immission point. The sound propagation direction of interest for the Dragaliden site (indicated by the dashed line) is $37^{\circ}$ used in Eq. (3) to be able to calculate the sound speed in Eq. (2) (courtesy of Google Earth). and a Nor1214 outdoor 1/2-in. microphone equipped with a rain hood and dust mesh. The sound level meter is a class 1 instrument and measures the sound spectra in $1 / 3$-octave bands in the frequency range of $10 \mathrm{~Hz}$ to $20 \mathrm{kHz}$. For the analysis, the instantaneous A-weighted 1/3-octave sound pressure levels with time weighting fast $(\mathrm{F})$ are sampled at $8 \mathrm{~Hz}$. The measurements were made continually for one year between 19 August 2011 and 19 August 2012 at the two sites. The sound level meter is connected to a modem so that data can be downloaded to a computer. The systems are powered from the grid by long cables extending through the forest. The instrument is calibrated regularly during site visits.

\section{B. Meteorological measurements}

Atmospheric data from different towers were collected simultaneously with the acoustical measurements. Tenminute average values of all the meteorological parameters were collected and vertical profiles were calculated. Throughout this paper, all wind directions are given by the meteorological convention, i.e., the direction from which the wind is blowing is stated. The setup is similar for the two measurement sites. One short meteorological mast, $18 \mathrm{~m}$ high, is equipped with WindSonic anemometers and ventilated temperature sensors at four levels (i.e., 0.5, 1.5, 5, and $18 \mathrm{~m}$ above the tower base), capturing wind speed, wind direction, and temperature. In addition to the short mast placed inside the forest, a taller mast is also used at each measurement site. At the Ryningsnäs site, a $140 \mathrm{~m}$ high mast placed near the WTs captures meteorological data at seven heights ranging from 25 to $140 \mathrm{~m}$. At the Dragaliden site, two meteorological masts are available: One $150 \mathrm{~m}$ high mast located $10 \mathrm{~km}$ southeast of the acoustical measurement site and one $123 \mathrm{~m}$ high mast located $7 \mathrm{~km}$ west of the site. The southeastern mast is located on a hill similar in height and shape to the hill where the WTs are placed, so the meteorological conditions are expected to be similar. The data from this meteorological mast were used throughout this paper except for the results presented in Fig. 6 for which data from the other mast were used because of loss of data from the southeastern mast. The western mast is located on a hill approximately $80 \mathrm{~m}$ higher than the hill were the WTs are standing. Overall, these meteorological data capture well how wind speed, wind direction, temperature, and relative humidity vary at the measurement sites. More detailed information about the meteorological sensors used in the present research is found in Tables I and II. In this paper, the amount of turbulence is given by the turbulence intensity (TI)

TABLE I. Meteorological equipment and measurement heights at the Ryningsnäs site. ws, wind speed; wd, wind direction; T, temperature; RH, relative humidity; and $\mathrm{P}$, atmospheric pressure.

\begin{tabular}{lll}
\hline \hline Height $(\mathrm{m})$ & Parameter & \multicolumn{1}{c}{ Instrument } \\
\hline 1.5 & RH, T, P & Rotronic HC2S3, Setra Barometer CS100 \\
60 & T & Thermocouple \\
100 & ws, wd & Thies FC, wind vane \\
120 & $\mathrm{u}$ & Thies FC \\
140 & $\mathrm{~T}$ & Thermocouple \\
\hline
\end{tabular}


TABLE II. Meteorological equipment and measurement heights at the Dragaliden site. ws, wind speed; wd, wind direction; T, temperature; $\mathrm{RH}$, relative humidity; and $\mathrm{P}$, atmospheric pressure.

\begin{tabular}{lll}
\hline \hline Height $(\mathrm{m})$ & Parameter & \multicolumn{1}{c}{ Instrument } \\
\hline 1.5 & RH, T, P & Rotronic HC2S3, Barometer Sensortechnics \\
3 & RH, T & Rotronic HC2S3 \\
4 & RH, T, P & Rotronic HC2S3, Vaisala PTB110 \\
51 & ws & Vaisala WAA252 \\
98 & T, ws & Rotronic HC2S3, Vaisala WAA252 \\
100 & RH, T, ws & Rotronic HC2S3, Vaisala WAA252 \\
111 & wd & NRG Ice Free II \\
120 & ws, wd & Vaisala WAA252 \\
136 & RH, T, P & Rotronic HC2S3, Vaisala PTB110 \\
\hline \hline
\end{tabular}

$$
T I=u^{\prime} / U
$$

where $u^{\prime}$ is the standard deviation and $U$ the mean of the wind speed, both calculated for periods of $10 \mathrm{~min}$. The time resolution of the wind speed was $1 \mathrm{~s}$. All gradients presented here are linear differences between two heights. The sound speed in a certain direction is calculated as

$$
c(z)=20.05 \sqrt{(1+0.61 q(z)) T(z)}+u_{\mathrm{comp}}(z),
$$

where $q$ is the specific humidity $(\mathrm{kg} / \mathrm{kg}), T(z)$ is the temperature $(\mathrm{K})$, and $u_{\text {comp }}(z)$ is the wind component $(\mathrm{m} / \mathrm{s})$ all given at height $z(\mathrm{~m})$. The wind component in a specified sound propagation direction $\left(^{\circ}\right)$ is given as

$$
u_{\text {comp }}(w d)=-|U| * \cos (w d-d i r),
$$

where $w d$ is the wind direction $\left(^{\circ}\right)$ in meteorological convention, dir is the specified sound propagation direction $\left(^{\circ}\right)$, i.e., $d i r=0^{\circ}$ northward propagation, dir $=90^{\circ}$ eastward propagation and $|U|$ is the magnitude of the wind $(\mathrm{m} / \mathrm{s})$.

\section{METHOD}

\section{A. Emitted sound power}

Operational data were obtained from the WT companies. Emitted sound power levels were calculated using Eqs. (4) and (5) from manufacturer's specifications and operational data. For both sites, the emitted sound power was related to the electric output of the WTs. A second-order polynomial fit between seven points for the Ryningsnäs site and six points for the Dragaliden site gives the following relations:

$$
\begin{aligned}
L_{\mathrm{W} \text { A, Ryningsnäs site }}= & -1.588 * 10^{-6} P^{2}+0.007 P \\
& +95.629, \\
L_{\mathrm{W} \text { A, Dragaliden site }}= & -2.843 * 10^{-6} P^{2}+0.011 P \\
& +91.127,
\end{aligned}
$$

where the constants have units $\mathrm{dB} /(\mathrm{kW})^{2}, \mathrm{~dB} / \mathrm{kW}, \mathrm{dB}$, and $P$ is the electric output of the turbine in $\mathrm{kW}$ and $L_{\mathrm{WA}}$ is the total sound power level over all 1/3-octave bands.

\section{B. Quantifying AM}

Standard measurement methods that measure sound pressure levels averaged over several minutes conceal WT sound characteristics, i.e., the characteristic swish sound. It is impossible to use the simple standard deviation of the sound pressure levels to describe whether or not AM is present because the turbine noise is sometimes more or less hidden in the background noise, and variations in that are often greater than the magnitude of the AM. When visiting the measurement sites on several occasions in different seasons, we observed that typical AM events last approximately $10-15 \mathrm{~s}$ followed by weaker AM. The method for detecting AM suggested here is based on the ideas of Lundmark. ${ }^{8}$ The method relies on a fast Fourier transform (FFT) of sound registrations over a short time period. It efficiently finds signals with specific periodicity and can detect AM from WTs in the presence of typical background noise.

The method consists of an FFT of the time series of Aweighted sound pressure levels (calculated from the 10 to $630 \mathrm{~Hz} \mathrm{1/3-octave} \mathrm{bands} \mathrm{only)} \mathrm{for} \mathrm{a} \mathrm{time} \mathrm{window} \mathrm{of} 15 \mathrm{~s}$. This frequency range was selected because WT sound often contains a clear low frequency component, while at greater distances, high-frequency WT sound is attenuated by atmospheric absorption, often resulting in effective masking by background sound. The sampling frequency of $8 \mathrm{~Hz}$ was chosen to give an adequate representation of the time variations with the time constant fast $(\mathrm{F})$. No window function is used in the FFT. The FFT will generate an amplitude modulation spectrum (AMS) for every $15 \mathrm{~s}$ period (seen in Fig. 3, to the right), which can quantify AM frequency and strength

$$
\mathrm{AMS} \equiv \sqrt{2} * \mid \operatorname{FFT}\left(L_{A, F, 8 \mathrm{~Hz}, 15 \mathrm{~s}) \mid / N}\right.
$$

where $N$ is the number of samples. Because periods of $15 \mathrm{~s}$ are analyzed using a sampling frequency of $8 \mathrm{~Hz}, N$ becomes 120. The AMS gives the different frequency components of the level variations, and it is independent of the absolute
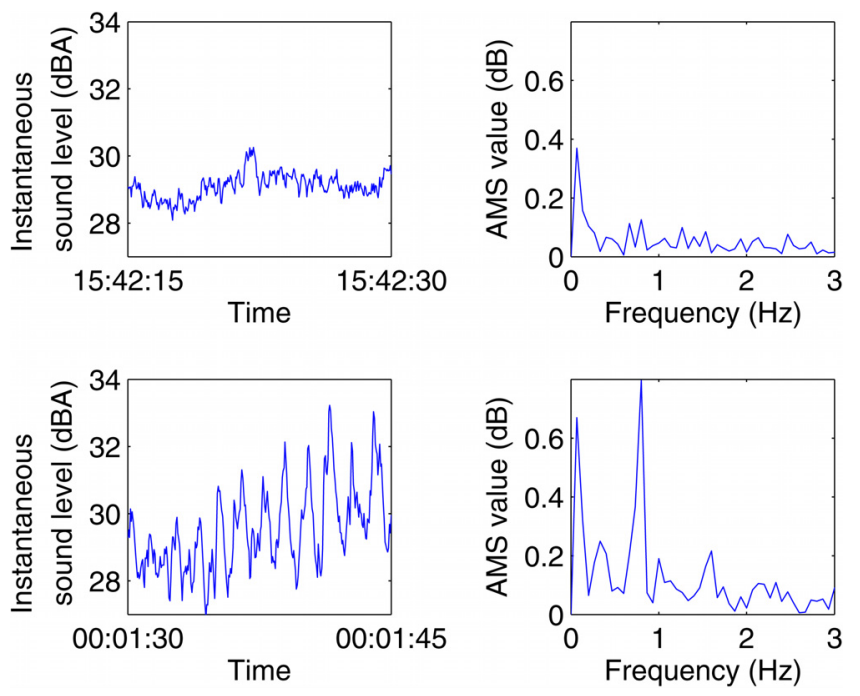

FIG. 3. (Color online) Sound level recording from the Dragaliden site on 20 July 2011 at different times. The measurements were made from microphone position $\mathrm{C}$ in Fig. 2. The AMS on the right detect periodical patterns at different frequencies from the $15 \mathrm{~s}$ periods indicated on the left. 
TABLE III. Number of measurements and selected measurements at different times of day: R, Ryningsnäs site and D, Dragaliden site.

\begin{tabular}{|c|c|c|c|c|}
\hline Location & $\begin{array}{l}\text { Number of measurements and percentage } \\
\text { of total measurements for specific times of day }\end{array}$ & $\begin{array}{c}\text { Night } \\
23: 00-6: 00\end{array}$ & $\begin{array}{c}\text { Evening } \\
\text { 19:00-23:00 }\end{array}$ & $\begin{array}{c}\text { Day } \\
6: 00-19: 00\end{array}$ \\
\hline R: Total & 52099 & 15271 & 8649 & 28179 \\
\hline R: Selected & $44128(84.7 \%)$ & $13616(89.2 \%)$ & $7645(88.4 \%)$ & $22867(81.2 \%)$ \\
\hline D: Total & 51066 & 14966 & 8560 & 27540 \\
\hline D: Selected & $36125(70.7 \%)$ & $10976(73.3 \%)$ & $6368(74.4 \%)$ & $18781(68.2 \%)$ \\
\hline
\end{tabular}

level of the sound; only the relative fluctuations are reflected. Because the level is given in decibels, AMS also is in decibel. Modern large WTs have typical blade passing frequencies of $0.6-1 \mathrm{~Hz}$ in production mode, so the AM factor is defined from the AMS for a given $15 \mathrm{~s}$ period,

$$
\begin{aligned}
\mathrm{AM} \text { factor } \equiv & \max [\operatorname{AMS}(f)], \\
& \text { within the range } 0.6 \mathrm{~Hz} \leq f \leq 1.0 \mathrm{~Hz} .
\end{aligned}
$$

Based on observations made at the measurement sites and on studies of various AMS, the AM of a $15 \mathrm{~s}$ period is defined as

$$
\begin{aligned}
& \mathrm{AM} \text { present } \equiv \mathrm{AM} \text { factor } \geq 0.4 \mathrm{~dB}, \\
& \mathrm{AM} \text { absent } \equiv \mathrm{AM} \text { factor }<0.4 \mathrm{~dB} .
\end{aligned}
$$

The continuous sound measurements are divided into $15 \mathrm{~s}$ parts and each time frame is analyzed. Figure 3 shows the instantaneous sound level and the AMS on two occasions, one with clear AM and one without AM.

\section{Selection of data}

The two measurement sites are very quiet with very little background sound from human activities. Typical background sound levels of approximately $16 \mathrm{dBA}$ are not uncommon on days with little wind. Even with such good measurement sites as these, accurate measurements of WT sound are difficult to make under windy conditions. The difficulties become greater as the distance between turbine and microphone increases and the signal approaches the background level. The wind speed at microphone height exceeds $2 \mathrm{~ms}^{-1}$ only approximately $1 \%$ of the time at our measurement sites. Wind noise in the microphone is rarely a problem when making measurements inside a dense forest. The most common sound that masks the WT sound is wind-induced sound from the vegetation. The AM detection method, however, can find signals even in the presence of moderate background noise. The selection criterion in this paper exclude measurements were the turbines are shut down or operate at a very low rate. All measurements where free field spreading from every turbine (treated as a point sources) contribute to a total sound pressure level of $30 \mathrm{dBA}$ or above in the immission point were selected for the analysis. Table III shows the number of selected measurements made at different times of day at the two measurement sites.

\section{RESULTS}

The method for quantifying AM was tested for one windy week at a reference site in a forest $30 \mathrm{~km}$ northwest of
Uppsala, Sweden. This site is similar to the two stationary measurement sites but without any WT present. Expected sound disturbance came from airplane flyovers, vegetationinduced sound, some birdsong, and a few distant passing cars. Although no WTs are present at the reference site, $2.6 \%$ of the total time is classified as amplitude modulated. This gives an estimate of the uncertainty of the method.

Continuous measurements of the instantaneous sound pressure levels were recorded eight times $\mathrm{s}^{-1}$ from 19 August 2011 to 19 August 2012 at the two measurement stations using stationary microphones. Figure 4 shows how often AM occurred at the Ryningsnäs site under various conditions. The distance from the closest WT is approximately $400 \mathrm{~m}$. AM is more frequent when winds are blowing from certain directions [seen in Fig. 4(a)]. The analysis is made more difficult because of influence from the turbine located further away from the immission point. Strictly downwind from the closest WT is at $285^{\circ}$ and strictly crosswind is at $195^{\circ}$ and $15^{\circ}$ which can be seen in Fig. 1. In Fig. 4(a), peaks can be seen in all directions mentioned even though the $15^{\circ}$ crosswind peak is weak and broad. The TI also seems to influence the rate of AM. Figure 4(b) shows that higher turbulence intensities at hub height tend to reduce how often AM is detected to some degree. The measured WT sound is more amplitude modulated during positive and negative sound speed gradients, as seen in Fig. 4(c). The sound is more rarely amplitude modulated at sound speed gradients close to zero at a distance of approximately $400 \mathrm{~m}$,
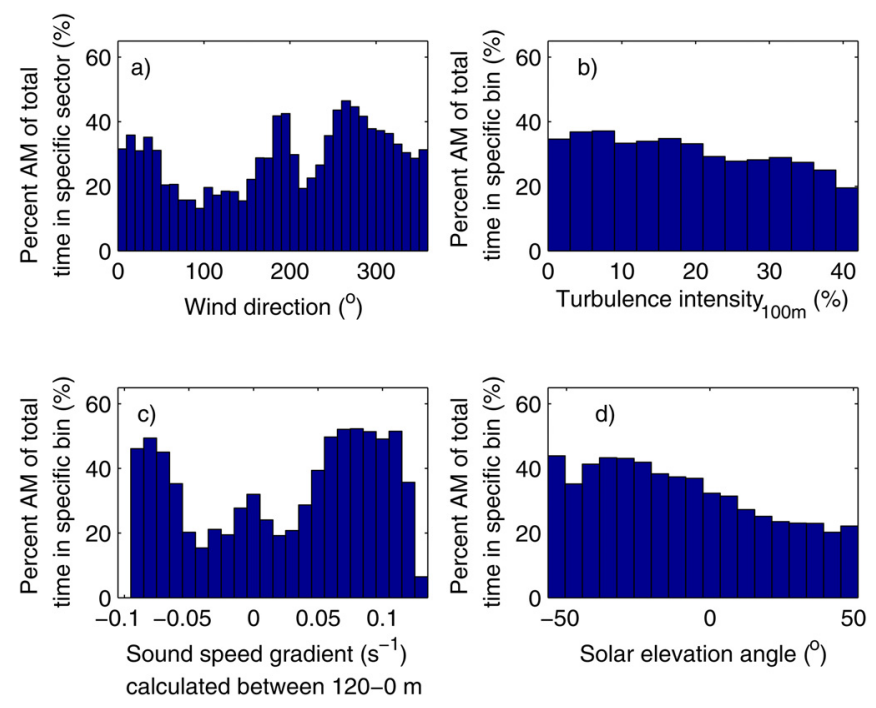

FIG. 4. (Color online) Percent of AM (AM measurement time divided by total time) in a specific bin for the Ryningsnäs site. 

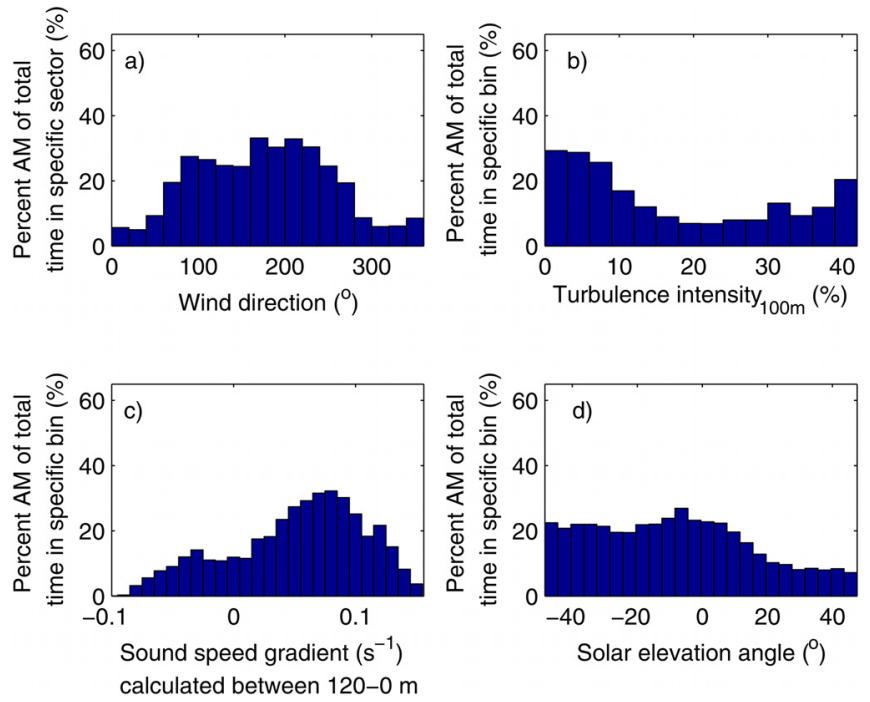

FIG. 5. (Color online) Percent of AM (AM measurement time divided by total time) in a specific bin for the Dragaliden site.

as seen in Fig. 4(c). It is also interesting to see how AM seems to be distributed over the day in Fig. 4(d). AM occurs more frequently in the morning, in the evening, and at night when the solar elevation angle is negative or close to zero. Note how the amount of AM increases with decreasing sun height in Fig. 4(d). This pattern follows the increase in the height of temperature inversions before sunset during clear evenings, which break up after sunrise. Figure 5 shows the long-term results for the Dragaliden site. The propagation distance is now approximately three times greater and the terrain is varying. The pattern is similar to that found at the
Ryningsnäs site although with some differences. From Fig. 5(a), it is seen how more AM seems to be detected in the wind direction sector in which the WTs are located, (see Fig. 2). For a specific wind direction, we can detect AM $33 \%$ of the time. AM seems to be very rare under upwind conditions, as seen in Fig. 5(a), and during negative sound speed gradients, shown in Fig. 5(c). This might be explained by WT sound waves being bent upward so no WT sound reaches the receiver. For the most positive numbers of the sound speed gradient shown in Fig. 5(c), less AM is detected. As for the Ryningsnäs site, less AM seems to be detected at high TI. For the Dragaliden site in Fig. 5(b), a rise in the amount of AM is detected at the highest turbulence intensities. This is probably because these conditions are very rare resulting in more uncertain results here.

$\mathrm{AM}$ is detected $33 \%$ of the time at the Ryningsnäs site and $19 \%$ of the time at the Dragaliden site.

Figure 6 shows AM results for a specific period of $30 \mathrm{~h}$ period at the Dragaliden site. A person was monitoring the measurements for the first $5 \mathrm{~h}$. The emission measurement point is microphone $\mathrm{A}$ and the immission point is microphone C, as shown in Fig. 2. It can be seen from Fig. 6(b) that the sound level at the immission point varies more in the day than at night. The evening and night, however, are associated with more AM. Human activities are a minor disturbing factor at this site, and the higher variation in sound levels in the day are thought to come from more vegetationinduced sound because of the changing meteorological conditions. The TI and wind speed profiles typically vary diurnally, with higher TI and smaller wind shear from 6 am to $7 \mathrm{pm}$ compared with night conditions. Although the WT
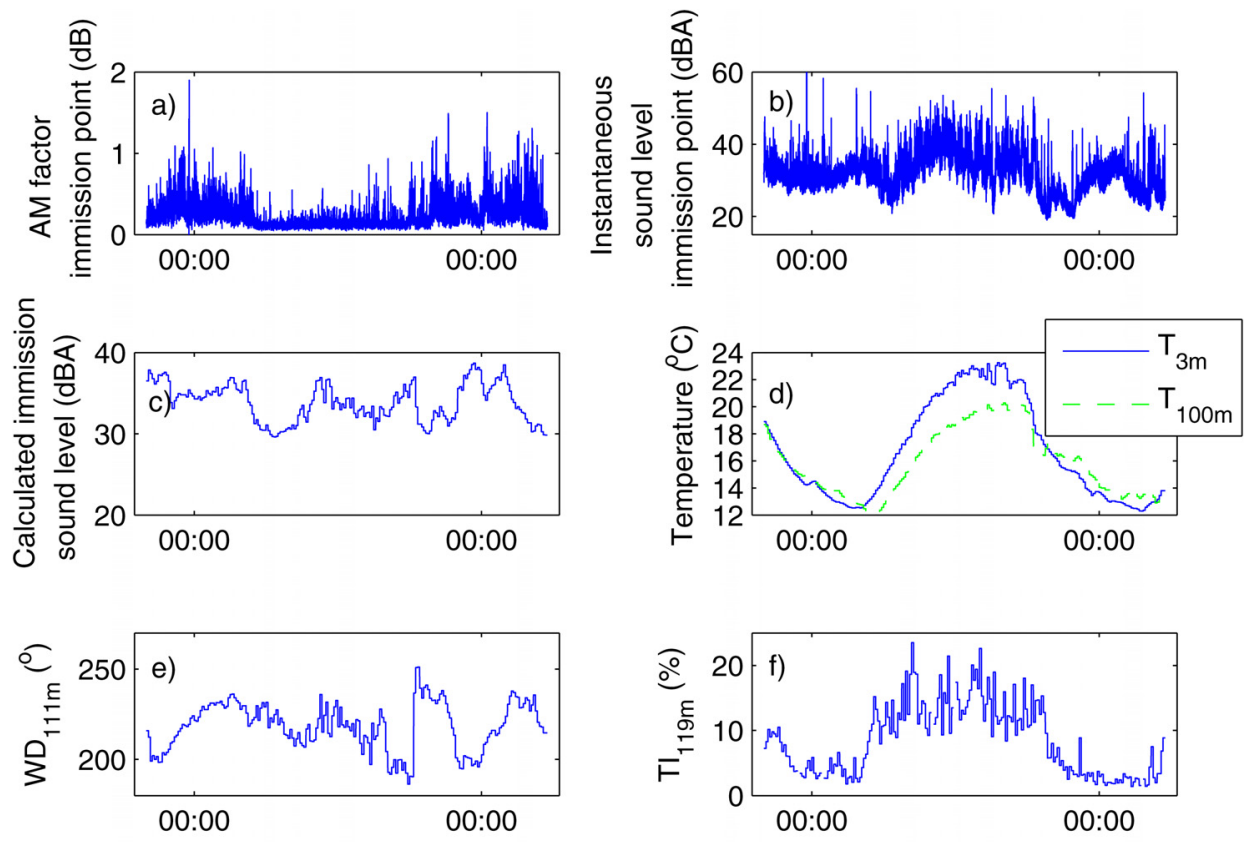

FIG. 6. (Color online) Thirty hours of AM detection at the Dragaliden site, 19-21 July 2011, and simultaneous 10 min meteorological average values. $\mathrm{TI}$ is the turbulence intensity. The emission point is at microphone position $\mathrm{A}$ and the immission point at microphone position $\mathrm{C}$ in Fig. 2. The calculated immission sound level was estimated using Eq. (5) and assuming spherical geometrical spreading of sound energy from a point source.
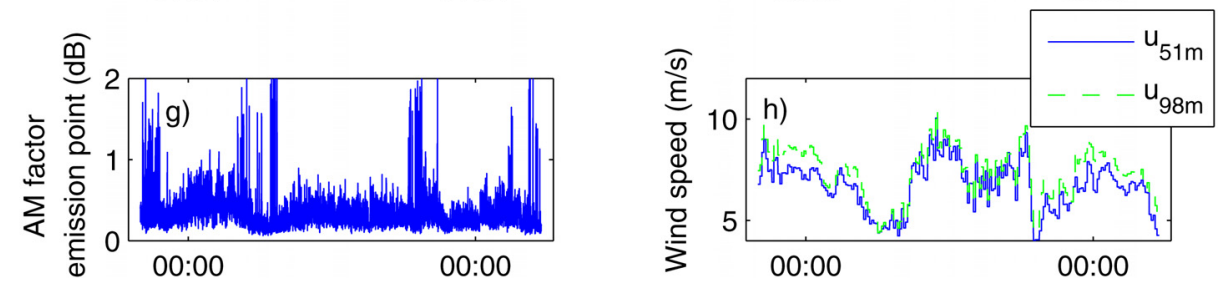
sound is more masked from 6 am to $7 \mathrm{pm}$ by vegetation sound, there were several occasions when the masking was minor and AM would be detectable if present. However, as seen in Fig. 6(a), just a few $15 \mathrm{~s}$ periods are classified as amplitude modulated from 6 am to $7 \mathrm{pm}$, suggesting that AM is uncommon at this time of day. As seen in Fig. 6(c), the sound power level emitted from the WTs was fairly steady except for lower levels for several hours in the morning and in the evening. As shown in Fig. 6(e), the wind direction changed little during these measurements, and was in the $180^{\circ}-250^{\circ}$ range throughout the period. This means that this measurement period is good for purposes of comparison. Figure 6(g) also shows the AM factor at the emission point. Some peaks occur in Fig. 6(g), associated with sudden much higher sound levels, probably due to tonality when the turbines nacelle direction is changing. The AM factor shown in Fig. 6(g) changes little over the period if the sudden peaks are not concerned. The measurement method would regard the sound as amplitude modulated most of the time at the emission point. Figure 6(a) shows a higher AM factor in the evening and at night, correlating well with the behavior of several meteorological parameters. It is well known that sound wave refraction occurs in the presence of wind and temperature gradients. ${ }^{9}$ In Fig. 6(a), AM is detected when the temperature inversion begins to rise from the ground in the evening, and less AM correlates with the break-up of the temperature inversion after sunrise, as seen in Fig. 6(d). The pattern is similar for wind speed. More AM occurs at the immission point under conditions of great wind speed difference between two heights as seen in Fig. 6(h). The TI seen in Fig. 6(f), around hub height also seems to be important. Higher TI results in less AM at the immission point and vice versa. Thus the specific combination of meteorological factors seems to be important for the occurrence of AM at a distance from WTs. Wind and temperature gradients bend the sound waves, resulting in higher WT sound levels in downwind conditions at the immission point in the evening and at night. This increases the chance of detecting the AM. The
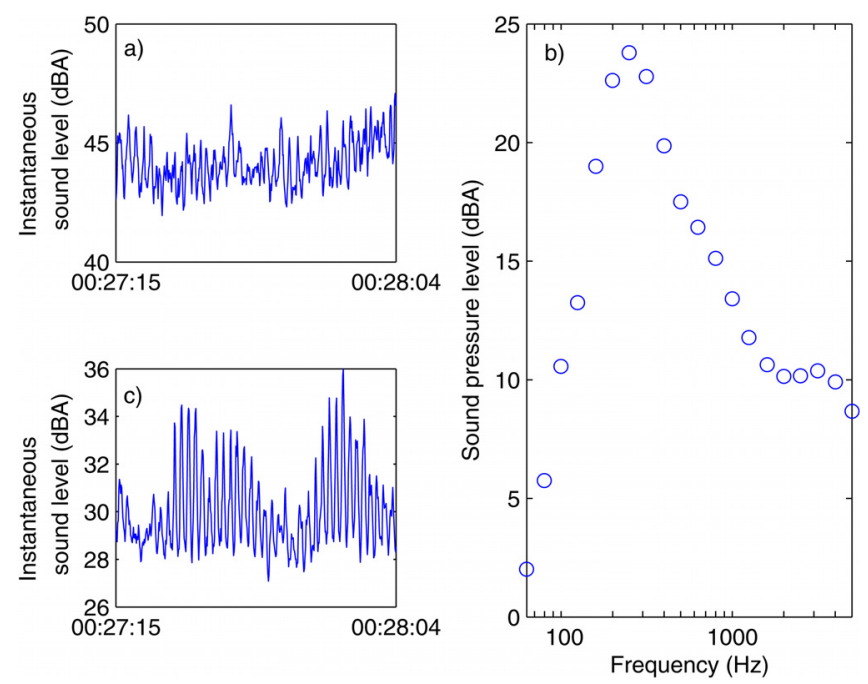

FIG. 7. (Color online) Emission (a) and immission (c) sound level measurements made at microphone positions $\mathrm{A}$ and $\mathrm{C}$ in Fig. 2 and the 1/3-octave band sound spectrum (b) for the time frame shown in (c). results for the specific day shown in Fig. 6 are in good agreement with the long-term results shown in Figs. 4 and 5.

It has been suggested that one important factor creating $\mathrm{AM}$ is sudden variations in the air flow the blades encounter. $^{7}$ This would mean that depending on the meteorological conditions at hub height, the AM produced by the WT should vary. This idea merits further investigation, but our measurements suggest that this is not the main reason for the detection of AM at immission points. The event presented in Fig. 7 displays much larger peak-to-peak values at the immission point than at the emission point in the same time frame, which indicates that the enhanced AM is influenced by the propagation path or the interference between several WTs rather than by changes in the emitted sound.

\section{DISCUSSION AND CONCLUSION}

Studying AM is very complex due the many factors that govern sound propagation from WTs. For an ideal analysis of how AM is produced and transmitted, emitted sound power, wind direction, temperature gradients, wind gradients, and turbulence would need to be known three dimensionally in small time steps. This is impossible to measure in the field, so simplifications must be made. Furthermore, the interaction of sound from several WTs complicate the analysis.

Higher prevalence of AM is detected when the sun is close to or under the horizon, which corresponds well with when temperature inversions occurs on clear nights. A temperature inversion near the ground changes the angle of incidence of the sound waves and affects the ground attenuation. The reflected sound waves are normally less damped if the sound comes more from the zenith than parallel to the ground. ${ }^{9}$ At the Dragaliden site when AM was present, a typical pattern was approximately $15 \mathrm{~s}$ of distinct AM followed by a minute of steadier sound levels.

Analyzing approximately $30 \mathrm{~h}$ of AM measurements recorded simultaneously at both an emission and an immission point shows that enhanced $\mathrm{AM}$ at an immission point could not be explained by enhanced AM at the emission point. It is instead an effect of interference between sound from several WTs or of different ray paths of the sound from one turbine. However, this last possibility requires further testing.

The AM detection method works well and does not react to passing cars, birds, or airplanes. During strong masking, the WT signal is lost using the detection method; the sound will of course not be experienced as amplitude modulated, but the signal may still be present in the background noise. We could conclude from our measurements that amplitude modulated sound from WTs is more common under certain meteorological conditions and is observable approximately $20 \%-30 \%$ of the operational time, depending on the distance from the turbines. In future studies, it would be interesting to investigate WT sound annoyance coupled to conditions with and without AM present.

\section{ACKNOWLEDGMENTS}

This study was financially supported by the Swedish Energy Agency. We are also grateful to Svevind, Vattenfall, Nordex, and Enercon for sharing operational and meteorological 
data. Johan Arnquist and Professor Emeritus Sven Israelsson at the Department of Earth Sciences, Uppsala University, Assistant Professor Karl Bolin at the Royal Institute of Technology, and consultant Hans Jonasson at the SP Technical Research Institute of Sweden gave us productive input. Gunnar Lundmark, of Lundmark Akustik and Vibration, and Professor Emeritus Kjell Ahlin at Blekinge Institute of Technology helped with the method for AM detection.

${ }^{1}$ H. M. E. Miedema and C. G. M. Oudshoorn, “Annoyance from transportation noise: Relationships with exposure metrics dnl and denl and their confidence intervals," Environ. Health Perspect. 109(4), 409-416 (2001).

${ }^{2}$ H. M. E. Miedema and H. Vos, "Noise annoyance from stationary sources: Relationships with exposure metric day-evning-night level (denl) and their confidence intervals," J. Acoust. Soc. Am. 116, 334-343 (2004).
${ }^{3}$ E. Pedersen and K. P. Waye, "Perception and annoyance due to wind turbine noise-a dose- response relationship," J. Acoust. Soc. Am. 116, 3460-3470 (2004).

${ }^{4}$ S. Oerlemans, P. Sijtsma, and B. M. Lopez, "Location and quantification of noise sources on a wind turbine," J. Sound Vib. 299, 869-883 (2007).

${ }^{5}$ S. Oerlemans and G. Schepers, "Prediction of wind turbine noise and comparison to experiment," in Second International Meeting on Wind Turbine Noise, INCE/Europe, Lyon, France (2007).

${ }^{6} \mathrm{G}$. P. van den Berg, "Effects of the wind profile at night on wind turbine sound," J. Sound Vib. 277, 955-970 (2004).

${ }^{7}$ G. P. van den Berg, "Do wind turbines produce significant low frequency sound levels?" in 11th International Meeting on Low Frequency Noise and Vibration, Maastricht, The Netherlands (2004).

${ }^{8}$ G. Lundmark, "Measurement of swish noise, a new method," in Fourth International Meeting of Wind Turbine Noise, INCE/Europe, Rome, Italy (2011).

${ }^{9} \mathrm{C}$. Larsson, "Effects of meteorological parameters on sound propagation," Ph.D. thesis, Acta Universitatis Upsaliensis, 1984. 